\title{
Identificação e seleção de espécies de Trichoderma spp. endofíticos de bromélias de restingas como agentes de biocontrole da fusariose em frutos de abacaxi
}

\author{
Gustavo de Andrade Bezerra ${ }^{1}$, Vicente Mussi-Dias ${ }^{1} \oplus^{\bullet}$, Pedro Henrique Dias dos $\operatorname{Santos}^{1}{ }^{\circledR}$,

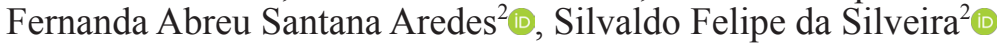

\begin{abstract}
${ }^{1}$ Laboratório de Entomologia e Fitopatologia; Laboratório de Genética e Melhoramento de Plantas. Universidade Estadual do Norte Fluminense Darcy Ribeiro. Av. Alberto Lamego, 200,0 CEP 28013-602, Campos dos Goytacazes, RJ, Brasil. ²Laboratório de Genética e Melhoramento de Plantas. Universidade Estadual do Norte Fluminense Darcy Ribeiro. Av. Alberto Lamego, 2000 CEP 28013-602, Campos dos Goytacazes, RJ, Brasil. Autor para correspondência: Gustavo de Andrade Bezerra (guandrade.b@gmail.com)
\end{abstract}

Data de chegada: 15/12/2017 Data de aceite: 01/11/2018

$10.1590 / 0100-5405 / 189165$

\section{RESUMO}

Bezerra, G.A.; Mussi-Dias, V.; Santos, P.H.D.; Aredes, F.A.S.; Silveira, S.F. Identificação e seleção de espécies de Trichoderma spp. endofíticos de bromélias de restingas como agentes de biocontrole da fusariose em frutos de abacaxi. Summa Phytopathologica, v.45, n.2, p.172-178, 2019.

Uma das doenças fúngicas de grande importância que ataca a cultura do abacaxizeiro é a fusariose, causado pelo fungo Fusarium guttiforme. A utilização do Trichoderma spp, que são fungos habitantes do solo e de ocorrência natural na forma endofítica em bromélias, ainda não foi estudada visando o biocontrole da gomose do abacaxizeiro. O trabalho objetivou identificar espécies de Trichoderma endofíticos de bromélias em Restinga e avaliar o antagonismo in vitro e in vivo a F. guttiforme, agente etiológico da gomose do abacaxi. Foram avaliados 5 isolados de Trichoderma mantidos em armazenamento na Clínica Fitossanitária da Universidade Estadual do Norte Fluminense Darcy Ribeiro (CF/UENF440, CF/UENF441, CF/UENF442, CF/UENF443 CF/UENF444). Um isolado de $F$. guttiforme patogênico ao abacaxizeiro também foi utilizado. Para identificação específica dos isolados de Trichoderma, efetuou-se a extração do DNA e o sequenciamento dos genes ITS. Procedeu-se a análise filogenética e os isolados endofíticos de bromélias foram agrupados na seção
Longibrachiatum e, com baixa homologia dentre as espécies conhecidas, podendo tratar-se, portanto, de nova espécie, o que ainda será confirmado com a obtenção de novas sequências de genes específicos. Foram realizados testes de antibiose in vitro para avaliação e seleção dos isolados antagonistas (antagonismo em cultivo pareado, efeito inibitório de compostos voláteis, não voláteis e não voláteis termoestáveis) e avaliou-se o tratamento biológico de frutos de abacaxi com ferimentos, visando-se avaliar o biocontrole da gomose em pós-colheita. O isolado CF/UENF440 se mostrou como um potencial agente de biocontrole in vitro de $F$. guttiforme, pois demonstrou forte antibiose em co-cultivo meio de cultura, tanto para compostos não-voláteis quanto para nãovoláteis termoestáveis, diferindo significativamente dos demais isolados testados e do controle. Na avaliação do biocontrole in vivo em frutos de abacaxi com ferimentos, os isolados de Trichoderma testados não apresentaram significativo efeito protetor no biocontrole da gomose em frutos na pós-colheita.

Palavras-chave: Antibiose, biocontrole.

\section{ABSTRACT}

Bezerra, G.A.; Mussi-Dias, V.; Santos, P.H.D.; Aredes, F.A.S.; Silveira, S.F. Identification and selection of Trichoderma spp. endophytic to bromeliacea from "restingas" as biocontrol agents of fusariosis in pineapples. Summa Phytopathologica, v.45, n.2, p.172-178, 2019.

One of the major fungal diseases affecting the pineapple crop is fusariosis, caused by the fungus Fusarium guttiforme. The use of Trichoderma spp., which are soil fungi naturally occurring as endophytic forms in Bromeliaceae, has not been studied for the biocontrol of fusariosis in pineapple plants. The present study aimed to identify Trichoderma species endophytic to Bromeliaceae in "Restinga" and to evaluate the in vitro and in vivo antagonism against $F$. gutifforme, the etiological agent of pineapple fusariosis. Five Trichoderma isolates were evaluated, which were stored in the Phytosanitary Clinics of the State University of North Fluminense Darcy Ribeiro (CF/UENF440, CF/UENF441, CF/UENF442, CF/UENF443 $\mathrm{CF} / \mathrm{UENF} 444)$. A F . guttiforme isolate, pathogenic to pineapple, was also used. For specific identification of Trichoderma spp., DNA extraction and sequencing and of ITS genes were carried out. Phylogenetic analysis was conducted and the endophytic isolates from Bromeliaceae were grouped in the Longibrachiatum section, showing low homology among the known species, which may indicate a new species that will be confirmed with the obtaining of additional sequences of specific genes. In vitro antibiosis tests were then carried out to select antagonistic isolates (antagonism in matched culture, inhibitory effect of volatile, non-volatile and non-volatile thermostable compounds) and the biological treatment of wounded pineapple fruits was evaluated with the aim of assessing the biocontrol of fusariosis in the post-harvest. The isolate CF/UENF440 was shown to be a potential in vitro biocontrol agent of $F$. guttiforme since it demonstrated strong antibiosis in cocultivation culture medium, for both non-volatile and non-volatile thermostable compounds, significantly differing from the remaining tested isolates and control. Considering the evaluation of in vivo biocontrol in wounded pineapple fruits, the tested Trichoderma isolates had no significant protectant effect in the biocontrol of fusariosis in post-harvest fruits.

Keywords: Antibiosis, biological control 
O abacaxi (Ananas comosus (L) Merril var. comosus Coppens e Leal) pertencente à família Bromeliaceae é originário da América do Sul e é frutífera de clima tropical e subtropical com grande importância econômica e social em mais de 70 países (6). Um dos fatores que mais interferem na produtividade desta fruteira é a presença de microrganismos causadores de doença, como os fungos que afetam diretamente no desenvolvimento, na qualidade e na produtividade de frutos desta cultura (7). No Brasil, a fusariose, doença causada pelo fungo Fusarium guttiforme Nirenberg e O‘Donnell (sin. Fusarium subglutinans $\mathrm{f}$. sp ananas) é considerada como a doença chave do abacaxizeiro, e a principal cultivar plantada é a Pérola suscetível à fusariose (1).

De maneira geral o controle da fusariose se fundamenta na integração de diversas práticas culturais, entre elas a aplicação de defensivos agrícolas durante o desenvolvimento das inflorescências. Dentre os muitos agentes potenciais de biocontrole, o fungo Trichoderma sp. tem sido um dos mais estudados, dado as suas características peculiares de antagonismo em condições naturais (15).

Conforme Luz (16), os bioprotetores apresentam-se como uma tecnologia alternativa para o controle de fitopatógenos e os microrganismos que apresentam esta capacidade, em especial Trichoderma, poderão ter um importante impacto na redução do uso de fungicidas químicos, no alcance da agricultura sustentável e na proteção da natureza. Os mecanismos de ação pelos quais Trichoderma pode atuar no controle biológico são: antibiose, competição, parasitismo e predação, podendo o antagonista agir por um ou mais mecanismos de interações. Inclusive, quando age por mais de um mecanismo, as chances do sucesso da capacidade de biocontrole são aumentadas (2).

Em avaliações realizadas com o objetivo de comprovar a efetividade de Trichoderma no controle de Fusarium spp. os resultados são positivos. Como exemplos, trabalhos mostraram que três isolados de Trichoderma sp. apresentam-se efetivos no controle de $F$. oxysporum f. sp. phaseoli, in vitro, quando inoculados 48 horas antes e simultaneamente com o fitopatógeno e, in vivo, um isolado foi efetivo no controle do fitopatógeno (20).

Considerando-se a eficácia de Trichoderma no controle biológico de doenças de plantas e conhecendo seu efeito de parasita e capacidade de estabelecer competição com outros microrganismos, o presente trabalho objetivou identificar espécies de Trichoderma endofíticos a bromélias do ecossistema Restinga e avaliar o antagonismo in vitro e in vivo a $F$. guttiforme, agente etiológico da fusariose do abacaxi.

\section{MATERIAL E MÉTODOS}

\section{Origem dos isolados de fungos}

Foram utilizados 5 isolados de Trichoderma mantidos em armazenamento na Clínica Fitossanitária da Universidade Estadual do Norte Fluminense Darcy Ribeiro (CF/UENF440, CF/UENF441, CF/ UENF442, CF/UENF443 CF/UENF444). As culturas foram isoladas de folhas de bromélias (Aechmea nudicaulis), do Parque Nacional de Restingas de Jurubatiba (PNRJ), localizado no litoral norte do estado do Rio de Janeiro. $\mathrm{O}$ isolado de $F$. guttiforme patogênico à abacaxi também foi obtido de armazenamento da Clínica Fitossanitária, sendo previamente armazenado em água destilada esterilizada (método Castellani).

Extração de DNA e sequenciamento para identificação de isolados de Trichoderma spp.
O DNA genômico dos fungos foi extraído por maceração da colônia do fungo utilizando-se protocolo de Santos et al. (28). Após a maceração, a extração foi feita pelo kit de purificação de DNA genômico da Promega (WizardGenomic DNA Purification Kit) (21). O DNA eluído foi armazenado a $-20{ }^{\circ} \mathrm{C}$ até sua utilização. A qualidade da extração do DNA genômico foi verificada por meio da eletroforese em gel de agarose $1 \%$. O gel consiste em $100 \mathrm{~mL}$ de solução TAE $1 \mathrm{X}$ e $1 \mathrm{~g}$ de agarose. Essa mistura foi dissolvida em forno micro-ondas e posteriormente resfriada para aplicação dos DNAs. Uma alíquota de $2 \mu \mathrm{L}$ de cada amostra de DNA foi misturada a $3 \mu \mathrm{L}$ de gelred e $3 \mu \mathrm{L}$ de blue Juice e aplicados ao gel de eletroforese em tampão TAE 1X. A corrida de eletroforese foi realizada a $80 \mathrm{~V}$ por 1 hora. Em seguida, o gel foi visualizado sob luz ultravioleta em fotodocumentador. Foi utilizado marcador Kasvi DNA Ladder, RTU modelo K9-100 L.

As reações de amplificação foram realizadas com os primers ITS1 (5' -TCCGTAGGTGAACCTGCGG-3”) e ITS4 (5"-TCCTCCGCTTATTGATATGC-3") (White et al. 1990). As condições da reação foram as seguintes: 50 ng de DNA, tampão PCR $1 \mathrm{x}, 1,5 \mathrm{U}$ de Taq polimerase, $0,06 \mu \mathrm{M}$ de primers ( $3 \mathrm{pmol} / \mathrm{reação)}$ ), 0,2 $\mathrm{mM}$ de cada dNTP, $1,5 \mathrm{mM}$ de $\mathrm{MgCl} 2$, e volume final de $50 \mu \mathrm{l}$. A amplificação foi realizada em termociclador modelo Veriti ${ }^{\circledR}$ Thermal Cycler, com desnaturação inicial a $94{ }^{\circ} \mathrm{C}$ por 2 minutos; 35 ciclos de 30 segundos a $94{ }^{\circ} \mathrm{C}, 1$ minuto a $55^{\circ} \mathrm{C}, 1$ minuto a $72{ }^{\circ} \mathrm{C}$; seguida de extensão final de 3 minutos a $72{ }^{\circ} \mathrm{C}$. Os produtos da amplificação da PCR foram visualizados e quantificados em gel de agarose $1 \%(\mathrm{p} / \mathrm{v})$ com o marcador de massa Kasvi DNA Ladder, RTU modelo K9-100 L.

Os produtos amplificados foram purificados utilizando o sistema comercial de purificação Agencourt AMPure XP (Ambion Magnetic Stand-96). As amostras purificadas foram enviadas para sequenciamento na empresa ACTGene Análises Moleculares Ltda (Centro de Biotecnologia, Universidade Federal do Rio Grande do Sul, Porto Alegre, RS, Brazil).

As sequências de nucleotídeos foram editadas com o software DNA Dragon (12). Todas sequências foram corrigidas manualmente e o arranjo dos nucleotídeos em posições ambíguas corrigidos utilizando as sequências dos primers no sentido 5'-3' e 3'-5'. As novas sequências foram depositadas no GenBank (http://www.ncbi.nlm.nih.gov).

A identificação dos isolados seguiu o protocolo sugerido pela Comissão Internacional de Taxonomia de Trichoderma e Hypocrea (ISTH), utilizando o programa TrichOKEY (3). Os isolados foram alocados na seção Longibrachiatum. Como a identidade dos isolados com as espécies do banco de dados da ISTH foi baixa, necessitou-se realizar estudo filogenético com espécies dentro desta seção.

\section{Análise filogenética}

Regiões consenso foram comparadas no banco de dados do GenBank utilizando o programa Mega BLAST. As novas sequências foram adicionadas ao conjunto de sequências obtido no Genbank e alinhadas no programa $\operatorname{MUSCLE}^{\circledR}$ (5) existente no software MEGA v. 5 (30). Espaços (Gaps) (inserções/deleções) foram tratados como inexistentes.

A análise de Inferência Bayesiana (BI) empregando o método da cadeia de Markov Monte Carlo (MCMC) foi realizada. MrMODELTEST (22) foi utilizado para selecionar o modelo de substituição de nucleotídeos para análise de BI. Os valores de verossimilhança foram calculados e o modelo selecionado de acordo com Akaike Information Criterion (AIC). O modelo de evolução selecionado para ITS foi HKY+I+G. A análise de BI foi concluída com MrBayes v.3.1.1 (26). As quatro cadeias MCMC foram conduzidas simultaneamente, iniciando 
Tabela 1. Isolados de Trichoderma incluídos na comparação filogenética de espécies endofíticas de bromélia

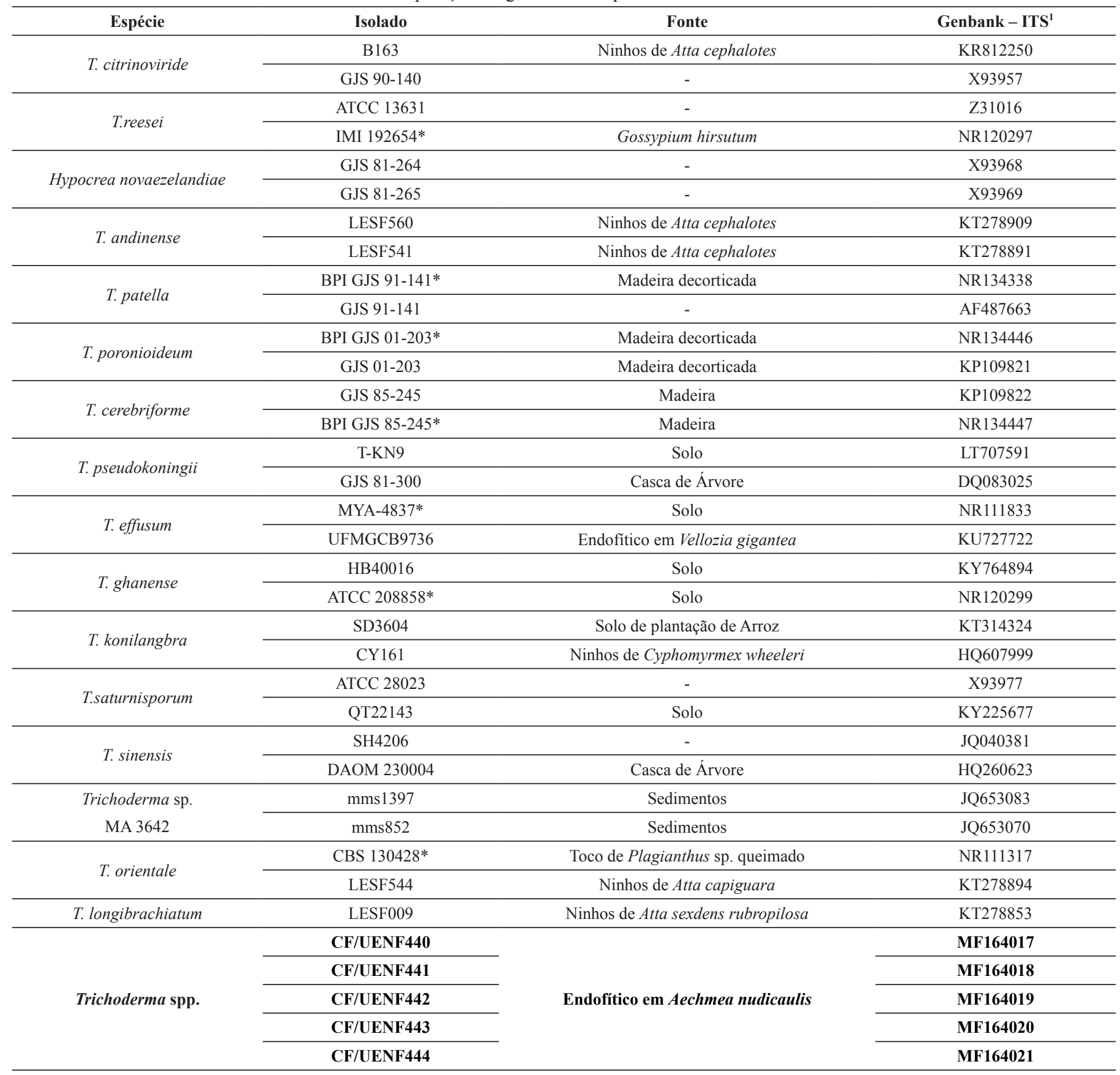

${ }^{1}$ ITS = internal transcribed spacer; *Espécie Tipo. Isolados obtidos neste estudo estão destacados em negrito.

as árvores aleatoriamente até 107 de gerações. As árvores foram amostradas a cada 1000 gerações, resultando em 10000 árvores. As primeiras 2500 árvores foram descartadas da análise. Os valores de probabilidade posterior (25) foram determinados da árvore consenso através das 7500 árvores remanescentes. A convergência dos log de verossimilhança foi analisada com o software TRACER v. 1.4.1 (24). A árvore foi visualizada no software FigTree (23) e exportada para programas gráficos. A espécie Penicillium glabrum SQU-QU09 foi utilizada como grupo externo (outgroup) nas análises.

\section{Antagonismo em cultura pareada}

$\mathrm{O}$ antagonismo dos isolados de Trichoderma contra $F$. guttiforme foi avaliado utilizando o método de pareamento de culturas, de acordo com Isaias et al. (13) modificado. A multiplicação dos isolados de Trichoderma e do patógeno, foi procedida em placas de Petri contendo o meio de batata-dextrose-ágar (BDA), mantidas a $25^{\circ} \mathrm{C}$ e fotoperíodo de $12 \mathrm{~h}$, por 7 dias. Posteriormente, discos de $5 \mathrm{~mm}$ de diâmetro foram retirados da cultura pura dos fungos e foram depositados a $1,0 \mathrm{~cm}$ de distância da borda da placa de Petri, contendo o mesmo meio. O antagonista foi posicionado no lado oposto ao patógeno e as placas foram mantidas nas mesmas condições descritas acima.

A avaliação do crescimento micelial foi realizada quando toda a superfície do meio se apresentava colonizada pelo $F$. guttiforme no tratamento controle com ausência do antagonista. O experimente foi 
realizado com seis repetições com os tratamentos (T0 - controle; T1 - CF/UENF440; T2 - CF/UENF441; T3 - CF/UENF442; T4 - CF/ UENF443; T5 - CF/UENF444) distribuídos ao acaso na câmara de crescimento. Com o termino do período de cultivo, foram realizadas as avaliações, onde foram proferidas as medidas do diâmetro das colônias do patógeno com o auxílio de régua milimetrada.

Ação inibitória de metabólitos voláteis, não-voláteis e termoestabilidade de não-voláteis de isolados de Trichoderma spp.

A avaliação do efeito inibidor de metabólitos voláteis (13) foi procedida com o uso de duas bases de placas de Petri de $90 \mathrm{~mm}$ de diâmetro, contendo BDA, que receberam individualmente, discos de $5 \mathrm{~mm}$, das culturas do patógeno e do antagonista. Após $24 \mathrm{~h}$, as bases contendo antagonista e patógeno foram sobrepostas e unidas com filme de PVC. Como testemunha, foram sobrepostas duas bases contendo o patógeno. As placas foram incubadas a $25^{\circ} \mathrm{C}$, com fotoperíodo de 12 h. Cada tratamento foi composto por seis repetições em delineamento inteiramente casualizado.

Posteriormente, para metabólitos não-voláteis, os isolados de Trichoderma foram cultivados em frascos Erlenmeyer contendo $250 \mathrm{~mL}$ de meio líquido contendo batata-dextrose. Foram incubadas em agitador orbital a $150 \mathrm{rpm}$, a $25^{\circ} \mathrm{C}$, em ausência de luz, durante cinco dias. Após esse período, a parte líquida foi filtrada em papel de filtro e centrifugada a $6.000 \mathrm{rpm}$ por 12 minutos. A fase líquida foi esterilizada em membrana de celulose $(0,45 \mu \mathrm{m})$ e incorporada ao meio BDA, na proporção de $25 \%$ (v/v). Foram preparadas seis placas com filtrado de cada antagonista, para confronto com o patógeno. Discos de ágar $(5 \mathrm{~mm})$ retirados de cultura do patógeno, foram depositados no centro de cada placa de Petri contendo meio BDA suplementado com filtrado de culturas do antagonista. As culturas foram incubadas a $25{ }^{\circ} \mathrm{C}$. O tratamento controle consistiu do patógeno cultivado na ausência de filtrados de culturas dos antagonistas. As avaliações do crescimento micelial foram realizadas quando toda a superfície do meio foi colonizada pelo $F$. guttiforme nas placas do tratamento controle.

Concomitantemente, realizou-se avaliação da termoestabilidade dos metabólitos não-voláteis produzidos por Trichoderma spp. Os procedimentos para avaliação foram conduzidos em paralelo com a avaliação de metabólitos não-voláteis, porém os filtrados de cultura foram previamente submetidos ao aquecimento a $121{ }^{\circ} \mathrm{C}$ por $20 \mathrm{~min}$, antes de serem plaqueados com meio de cultivo. Utilizou-se seis placas para cada agente obtido dos antagonistas. O tratamento controle consistiu do patógeno. As avaliações do crescimento micelial foram realizadas quando toda a superfície do meio foi colonizada pelo $F$. guttiforme nas placas do tratamento controle.

\section{Teste de biocontrole in vivo}

Para avaliar a eficácia do antagonismo mediado por isolados de Trichoderma spp. contra o fungo patogênico $F$. guttiforme, agente causal da gomose do abacaxi, foi realizado um teste in vivo em frutos de abacaxi. Foram utilizados frutos de abacaxi da cultivar Pérola, suscetível à doença. Os frutos utilizados foram selecionados de acordo com o estágio de maturação, que foi o estagio 1, em que os segmentos do fruto são, na sua parte central, de cor verde, passando a verde bem escuro na sua periferia e a marrom escuro nos sulcos divisórios.

Os frutos passaram por desinfestação superficial, onde foram mergulhados em hipoclorito de sódio (água sanitária comercial) a $0,5 \%$ para limpeza, por 5 minutos e colocados em bancada para secagem. Após a secagem, receberam uma perfuração de $1 \mathrm{~cm}$ de profundidade, na região do terço inferior, utilizando-se, para isso, uma ponteira de $100 \mathrm{uL}$ de capacidade. Posteriormente, os frutos foram imersos em suspensão de $10^{7}$ conídios/mL obtida individualmente de cada um dos cinco isolados de Trichoderma spp. A imersão ocorreu por um tempo de 2 minutos seguida por incubação dos frutos em câmara úmida por 24 horas para aderência da suspensão e inicio do crescimento do antagonista nos frutos. Passado esse período, os frutos foram inoculados, nos orifícios anteriormente feitos, com um disco de $0,5 \mathrm{~cm}$ da colônia da cultura pura de $F$. guttiforme, permanecendo em câmara úmida por mais 48 horas. Após esse tempo, os frutos foram retirados de câmara úmida e deixados em bancada de 7 a 10 dias até a avaliação da infecção.

Foram utilizados 4 frutos para cada tratamento que consistiu de: $\mathrm{T} 1$ - controle sem $F$. guttiforme (fruto sem tratamento com antagonista e sem a inoculação de $F$. guttiforme; T2 - controle com $F$. guttiforme (fruto sem tratamento com antagonista e com inoculação do fungo patogênico); T3 - suspensão do isolado CF/UENF440; T4 - suspensão do isolado CF/UENF441; T5 - suspensão do isolado CF/UENF442; T6 - suspensão do isolado CF/UENF443; T7 - suspensão do isolado $\mathrm{CF} / \mathrm{UENF} 444$. O ensaio foi repetido três vezes. Os frutos foram abertos e foram realizados medidas de largura, comprimento e área da lesão formada pelo fungo patogênico em todos os tratamentos.

\section{Análises estatísticas}

Para cada isolado, realizou-se um teste de comparação de médias de inibição de crescimento do patógeno $F$. guttiforme sob efeito inibitório por metabólitos voláteis, não-voláteis, termoestáveis e biocontrole in vivo através do teste de Skott-knott, considerando o nível de 5\% de significância estatística. $\mathrm{O}$ mesmo foi aplicado ao biocontrole in vivo. Para as análises adotou-se o programa de linguagem estatística $\mathrm{R}$, livre para download no síte http://www.r-project.org/. Utilizou-se o pacote ExpDes para obtenção das análises.

\section{RESULTADOS E DISCUSSÃO}

\section{Identificação de espécies de Trichoderma spp.}

A análise filogenética foi realizada com 38 táxons e o alinhamento das sequências resultou num total de 746 caracteres, dos quais 89 foram informativos para parcimônia, 227 foram variáveis e 473 foram conservados. Pela análise fillogenética utilizando o gene ITS foi possível a identificação de um novo clado, bem suportado ( $\mathrm{pp}=0.99)$, entre os clados de $T$. andinense e $T$. citrinoviride, indicando a possibilidade de estes isolados pertencerem à uma nova espécie. Todos os isolados de bromélias estudados parecem se tratar de uma mesma espécie de Trichoderma spp., com base na análise filogenética.

Os isolados foram alocados na seção Longibrachiatum, porém a identidade dos isolados com as espécies do banco de dados da ISTH foi baixa. Taxonicamente, Trichoderma foi dividido em cinco seções, incluindo a seção Longibrachiatum, mas com análises filogenéticas moleculares crescentes, a nomenclatura seccional de Trichoderma foi abandonada em favor da nomeação de clados filogenéticos (14). Curiosamente, porém, a seção distintiva morfológica e metabólica Longibrachiatum é uma das duas únicas seções que permaneceu intacta na sequência da análise filogenética (4).

O clado Longibrachiatum compreende as espécies de Trichoderma mais intensamente estudadas, compreende espécies que são utilizadas industrialmente na produção de enzimas celulolíticas e hemicelulases envolvidas na indústria alimentar, têxteis e tecnologia biocombustível $(8,14)$. 


\section{Avaliação do antagonismo em cultura pareada}

Para o antagonismo em cultivo pareado, avaliou-se inibição do crescimento micelial de $F$. guttiforme confrontado com os 5 isolados de Trichoderma. Os isolados CF/UENF441, CF/UENF442 e CF/ UENF443 foram os que apresentaram inibição de crescimento micelial do agente patogênico, com $82.62 \%, 83.3 \%$ e $80.63 \%$, respectivamente de percentuais de inibição de crescimento micelial.

A maior inibição de crescimento micelial de F. guttiforme a 5 isolados de Trichoderma pode estar relacionada à origem dos isolados de Trichoderma, já que os mesmos foram obtidos de forma endofítica em bromeláceas de restinga. Como $F$. guttiforme foi isolado de abacaxi infectado, pode-se supor que os isolados de Trichoderma provenientes de bromeleaceas tenham uma ação mais efetiva do que os provenientes de outras culturas e apresente estratégia de defesa mais eficazes.

O Trichoderma utiliza diferentes mecanismos de ação contra seus competidores, incluindo ação direta, degradação e uso de carboidratos complexos pela ação de enzimas produzidas (10), tornando-os, como um dos mais bem-sucedido colonizadores dos seus habitats (29).

Os fungos com mecanismos antagonistas utilizam diferentes mecanismos de interações com patógenos. A avaliação de cultura pareada serve para selecionar isolados que tenham maior atividade antagônica e de micoparasitismo (19). Nas aplicações de antagonistas no controle de fitopatógenos têm sido utilizadas diferentes espécies de isolados Trichoderma e a antibiose tem sido considerada um dos principais mecanismos de ação realizados pelo antagonista (27).

Efeito inibitório de metabólitos voláteis, não-voláteis e nãovoláteis termoestáveis produzidos por isolados de Trichoderma spp.

A inibição de crescimento de $F$. guttiforme mediado pelo efeito inibitório de metabólitos voláteis, não-voláteis e não-voláteis termoestáveis de isolados de Trichoderma spp. está representado na Tabela 2. Para os metabólitos voláteis, os isolados CF/UENF441, CF/ UENF442, CF/UENF443, CF/UENF444, foram os que apresentaram menores média de crescimento de $F$. guttiforme, onde os percentuais de inibição de crescimento promovido pela ação antagônica de Trichoderma spp. variam de $67,30 \%$ a $71,66 \%$, mostrando que os isolados dos antagonistas atuam diretamente na inibição de crescimento do agente patogênico por ação de metabólitos voláteis.

Para metabólitos não-voláteis e não voláteis termoestáveis, o isolado CF/UENF440 foi o que se mostrou promissor na inibição de crescimento de $F$. guttiforme segundo demostra os dados estatísticos da Tabela 2.

Os dados de percentuais de inibição de crescimento, mostram que o isolado endofítico CF/UENF440, apresentou $88,43 \%$ de inibição para o ensaio de metabólitos não-voláteis e de 77,30\% para o ensaio de metabólitos não-voláteis termoestáveis. Esses dados mostram que o Trichoderma spp. vem se mostrado como um agente promissor de biocontrole de $F$. guttiforme in vitro.

$\mathrm{Na}$ avaliação, os metabólitos voláteis, não-voláteis e nãovoláteis termoestáveis produzidos pelos isolados de Trichoderma, proporcionaram uma variação no percentual de inibição do crescimento micelial desse patógeno, dependendo do metabólito avaliado. Os resultados mostraram que $F$. guttiforme foi mais suscetível a ação dos metabólitos não-voláteis e não-voláteis termoestáveis produzidos pelos isolados de Trichoderma, com inibição acima de 70\%.

No teste de termoestabilidade, os metabólitos de Trichoderma spp. se mantiveram ativos mesmo após autoclavagem, pois inibiram o crescimento micelial do patógeno, indicando o potencial desses metabólitos antifúngicos, nas condições experimentais utilizadas.

Gruber \& Seidel-Seiboth (9), avaliaram e constataram que, o crescimento em direção à hifa do patógeno, o Trichoderma produz metabólitos voláteis e enzimas hidrolíticas que, ao degradar a parede celular do patógenos e ativam a expressão de genes envolvidos no micoparasitismo.

Vários estudos apontam uma susceptibilidade dos fungos fitopatogênicos a metabólitos produzidos por antagonistas, inclusive por isolados de Trichoderma spp. A capacidade de Trichoderma produzir metabólitos secundários e o seu efeito fungicida pode variar entre espécies, entre isolados da mesma espécie e de suas fontes de isolamento, como ocorre com os endofíticos e em função dos compostos antifúngicos secretados (17).

\section{Biocontrole in vivo de $F$. guttiforme em frutos de abacaxi}

Nas análises realizadas nos testes in vivo para avaliação do potencial de biocontrole de $F$. guttiforme com suspensões de isolados de Trichoderma spp. endofíticos, pode-se constatar que os isolados do antagonista não apresentaram efeito de biocontrole sobre o agente patogênico aplicando-se esta metodologia. Na tabela 3, no parâmetro comprimento da lesão não houve diferença significativa entre o controle e os isolados e o controle. O mesmo aconteceu com o parâmetro largura e área das lesões, onde os isolados CF/UENF440 e CF/UENF443 obtiveram médias relativamente mais altas que o controle.

Com as análises realizadas, ressalta-se que os isolados não proporcionaram efeito antagônico contra o F. guttiforme. Os metabólitos produzidos pelos isolados sob condições controladas podem se distinguir funcional e quantitativamente daqueles presentes nos ferimentos em fruto. Isto pode ocorrer devido a variações nas condições de temperatura, umidade, fatores nutricionais e estagio de maturação

Tabela 2 - Médias (mm) do diâmetro das colônias de F. guttiforme por metabólitos voláteis, não-voláteis e não voláteis termoestáveis produzidos por isolados de Trichoderma spp.

\begin{tabular}{cccc}
\hline & \multicolumn{3}{c}{ Efeito inibitório } \\
\cline { 2 - 4 } & Voláteis & Não-voláteis & Termoestáveis \\
\hline Controle & $83,00 \mathrm{a}$ & $77,00 \mathrm{a}$ & $77,00 \mathrm{a}$ \\
CF/UENF440 & $54,08 \mathrm{~b}$ & $26,00 \mathrm{~d}$ & $36,66 \mathrm{e}$ \\
CF/UENF441 & $47,16 \mathrm{c}$ & $34,91 \mathrm{c}$ & $50,00 \mathrm{~b}$ \\
CF/UENF442 & $45,08 \mathrm{c}$ & $42,75 \mathrm{~b}$ & $42,91 \mathrm{~d}$ \\
CF/UENF443 & $44,16 \mathrm{c}$ & $33,33 \mathrm{c}$ & $46,66 \mathrm{c}$ \\
CF/UENF444 & $43,50 \mathrm{c}$ & $42,25 \mathrm{~b}$ & $40,66 \mathrm{~d}$ \\
\hline CV(\%) & 12,53 & 7,70 & 4,89 \\
\hline
\end{tabular}

Letras iguais mostram que o isolado não difere entre si quanto à inibição do patógeno por compostos voláteis, não-voláteis e não-voláteis termoestáveis, segundo o teste de Skott-knott, ao nível de 5\% de significância estatística. 
Tabela 3 - Comparação do crescimento de lesões de Fusarium guttiforme em frutos de abacaxi protegidos com suspensão de por isolados de Trichoderma spp.

\begin{tabular}{cccc}
\hline \multicolumn{5}{c}{ Biocontrole de $\boldsymbol{F}$. guttiforme } & & \\
\hline & Comprimento $(\mathbf{c m})$ & Largura $(\mathbf{c m})$ & Área $\left(\mathrm{cm}^{2}\right)$ \\
\hline Controle com $\boldsymbol{F}$. guttiforme & $3,725 \mathrm{a}$ & $3,750 \mathrm{~b}$ & $14,267 \mathrm{~b}$ \\
CF/UENF440 & $3,675 \mathrm{a}$ & $5,825 \mathrm{a}$ & $24,400 \mathrm{a}$ \\
CF/UENF441 & $3,575 \mathrm{a}$ & $4,125 \mathrm{~b}$ & $14,957 \mathrm{~b}$ \\
CF/UENF442 & $3,875 \mathrm{a}$ & $4,125 \mathrm{~b}$ & $29,130 \mathrm{a}$ \\
CF/UENF443 & $4,200 \mathrm{a}$ & $6,975 \mathrm{a}$ & $14,267 \mathrm{~b}$ \\
CF/UENF444 & $3,750 \mathrm{a}$ & $3,875 \mathrm{~b}$ & 32,01 \\
\hline CV (\%) & 11,74 & 26,57 & \\
\hline
\end{tabular}

Letras iguais mostram que o isolado não difere entre si quanto à inibição do patógeno volátil, não-volátil e não-volátil termoestável, segundo o teste de Skott-knott, ao nível de 5\% de significância estatística.

dos frutos. Além disso, a ação antagonista pode resultar do efeito sinérgico da atividade enzimática dos fungos nos tecidos internos do fruto. Assim, faz-se necessário avaliar se os isolados oferecem proteção as mudas e durante a floração no campo.

Uma hipótese que pode ser levantada a respeitos dos dados obtidos no experimento é que, no momento de interação entre os isolados endofíticos de Trichoderma spp. com o $F$. guttiforme, a ação de enzimas hidrolíticas secretadas pelo antagonista pode ter efetuado um sinergismo sobre o fungo patogênico, potencializando sua ação no fruto, aumentando o tamanho e a área da lesão.

Segundo Huang et al. (11), o processo de como os agentes de biocontrole efetivamente atuam na proteção é um requisito para sua aplicação prática, exemplo disso, na identificação dos genes que são expressos preferencialmente e que podem significar um determinado processo biológico.

Para Trichoderma spp., o mecanismo de biocontrole mais aceito tem sido o micoparasitismo mediado pela produção de quitinases e outras enzimas que degradam a parede célular do patógeno (9). Em estudos in vitro, confrontando-se Trichoderma spp. com F. culmorum e F. graminearum, os resultados mostraram uma regulação positiva de todos os genes testados durante o micoparasitismo, indicando o envolvimento de enzimas quitinolíticas nessa interação (18). Todavia, em frutos de abacaxi, a metodologia utilizada não possibilitou a avaliação e a atividade de enzimas sobre o patógeno pode não ter sido expressa ou rápida ao ponto de impedir a rápida infecção de $F$. guttiforme em frutos com ferimento na pós-colheita.

Os Isolados de Trichoderma spp. endofíticos de bromeliáceas de restingas, realizada segundo analise filogenética com base no gene ITS, propõe que estes isolados, (CF/UENF440, CF/UENF441, CF/ UENF442, CF/UENF443, CF/UENF444), pertencem a uma provável nova espécie do clado Longibrachiarum.

Para os testes de antagonismo em culturas pareadas para inibir crescimento de $F$. guttiforme, o isolado CF/UENF440, se mostrou como um potencial agente de controle in vitro do agente patogênico.

Para avaliação do efeito inibitório por metabólitos voláteis, os isolados CF/UENF441, CF/UENF442, CF/UENF443, CF/UENF444 não apresentaram diferença significa na inibição de crescimento do agente patogênico; na avaliação dos metabólitos não-voláteis e nãovoláteis termoestáveis, destaca o isolado CF/UENF440 como potencial inibidor de crescimento de $F$. guttiforme, resultado esse, se equiparando com o teste de antagonismo por pareamento de culturas.

$\mathrm{Na}$ avaliação do biocontrole in vivo em frutos de abacaxi com ferimentos, os isolados do antagonista não apresentaram efeito sobre o agente patogênico $F$. guttiforme.

\section{AGRADECIMENTOS}

À Coordenação de Aperfeiçoamento de Pessoal de Nível Superior (CAPES) e Fundação de Amparo à Pesquisa do Estado do Rio de Janeiro (FAPERJ).

\section{REFERÊNCIAS}

1. Aquije, G.M.F.V.; Zorzal, P.B.; Buss, D.S.; Ventura, J.A.; Fernandes, P.M.B.; Fernandes, A.A.R. Cell wal alterations in the leaves of fusariosis resistent and susceptible pineapple cultivars. Plant Cell Reports, Zurique, v.9, n.10, p.1109-1117, 2010.

2. Bettiol, W. Métodos Alternativos para o Controle de Doenças de Plantas. In: Michereff, S.J.; Barros, R. Proteção de plantas na agricultura sustentável. Recife: Universidade Federal Rural de Pernambuco, 2001.

3. Druzhinina, I.; Koptchinski, A.; Komon, M.; Bissett, J.; Szakacs, G.; Kubicek, C.P. An oligonucleotide barcode for species identification in Trichoderma and Hypocrea. Fungal Genetic and Biology, v.42, p.813-828, 2005.

4. Druzhinina, I.S.; Komon-Zelazowska, M.; Ismaiel, A.; Jaklitsch, W.M.; Mulaw, T.; Samuels, G.J.; Kubicek, C.P. Molecular phylogeny and species delimitation in the Longibrachiatum Clade of Trichoderma. Fungal Genetic and Biology, v.49, n.5, p.358-368, 2012.

5. Edgar, R.C. MUSCLE: multiple sequence alignment with high accuracy and high throughput. Nucleic Acids Research, v.32, p.1792-1797, 2004.

6. França-Santos, A.; Alves, R.S.; Leite, N.S; Fernandes, R.P.M. Estudos bioquímicos da enzima bromelina do Ananas comosus (abacaxi). Scientia Plena: Recursos Genéticos e Melhoramento de Plantas para o Nordeste Brasileiro, Aracajú, v.5, n.11, p.1-6, 2009.

7. Granada, G.G.; Zambiaz, R.C.; Mendonça, C.R.B. Abacaxi: produção, mercado e subprodutos. Curitiba: C. CEPPA, 2004.

8. Gal-Hemed, I.; Atanasova, L.; Komon-Zelazowska, M.; Druzhinina, I.S.; Viterbo, A.; Yarden, O. Isolados marinhos de Trichoderma como possíveis agentes halotolerantes de controle biológico para zonas áridas agricultura. Applied Environmental Microbiology, v.77, n.15, p.5100-5109, 2011.

9. Gruber, S.; Seidl-Seiboth, V. Self versus non-self: fungal cell wall degradation in Trichoderma. Microbiology, v.158, p.26-34, 2012.

10. Harman, G.E.; Howell, C.R.; Viterbo, A.; Chet, I.; Lorito, M. Trichoderma species - opportunistic, avirulent plant symbionts. Nature reviews/Microbiology, v. 2, n.1, p.43-56, 2004.

11. Huang, X.; Li, Y.; Niu, Q.; Zhang, K. Suppression Subtractive Hybridization (SSH) and its modifications in microbiological research. Applied Microbiology and Biotechnology, v.76, n.4, p.753-760, 2007

12. Hepperle, D. DNA Dragon 1.4.1 - DNA Sequence Contig Assembler Software. 2011. Disponível em: <www.dna-dragon.com>. Acesso em: 22 maio 2017.

13. Isaias, C.O.; MartinS, I.; Silva, J.B.T.; Silva, J.P.; Mello, S.C.M. Ação antagônica e de metabólitos bioativos de Trichoderma spp. contra os pató- 
genos Sclerotium rolfsii e Verticillium dahliae. Summa Phytopathologica, Botucatu, v.40, n.1, p.34-41, 2014.

14. Kubicek, C.P.; Mikus, M.; Schuster, A.; Schmoll, M.; Seiboth, B. Estratégias de engenharia metabólica para a melhoria da produção de celulase pela Hipocereia jecorina. Biotechnology Biocombustíveis, v.2, p.19, 2009.

15. Lohmann, R.T.; Pazuch, D.; Stangarlin, J.R.; Selzlein, C.; Nacke, H. Seleção de isolados de Trichoderma spp. para controle de Sclerotium rolfsii em soja. Revista Brasileira de Agroecologia, v.2, n.2, p.1665-1668, 2007.

16. Luz, W.C. Efeito de bioprotetores em patógenos de sementes e na emergência e rendimento de grãos de milho. Fitopatologia Brasileira, v.26, n. 1, p. 16-20, 2001.

17. Lorito, M.; Woo, S.L.; Harman, G.E.; Monte, E. Translational research on Trichoderma: from 'omics to the field. Annual Review Phytopathology, v.498, p.395-417, 2010.

18. Matarese, F.; Sarrocco, S.; Gruber, S.; Seidl-Seiboth, V.; Vannacci, G. Biocontrol of Fusarium head blight: interactions between Trichoderma and mycotoxigenic Fusarium. Microbiology, v.158, p.98-106, 2012.

19. Mello, S.C.M.; Ávila, Z.R.; Braúna, L.M.; Pádua, R.R.; Gomes, D. Cepas de Trichoderma spp. para el control biológico de Sclerotium rolfsii Sacc. Fitosanidad, v.11, n.1, p.3-9, 2007.

20. Pandolfo, J.D. Associação de Trichoderma sp. a fungicidas no controle de Fusarium oxysporum f. sp. Phaseoli. 2007. 78p. Dissertação (Mestrado em Fitotecnia) - Universidade Federal do Rio Grande do Sul, Porto Alegre.

21. Pinho, D.B.; Dutra, D.C.; Pereira, O.L. Notes on Ceratocystis paradoxa causing internal post-harvest rot disease on immature coconut in Brazil. Tropical Plant Patholology, v.38, p.152-157, 2013.
22. Posada, D.; Buckley, T.R. Model selection and model averaging in phylogenetics: advantages of Akaike information criterion and Bayesian approaches over relationships ratio tests. Systematic Biology, v.53, p.793-808, 2004.

23. Rambaut, A. FigTree 1.2.2. 2009. Disponível em: <tree.bio.ed.ac.uk/software/figtree>. Acesso em: 22 maio 2017.

24. Rambaut, A.; Drummond, A.J. Tracer version 1.2. 2013. Disponível em: $<$ http://evolve.zoo.ox.ac.uk>. Acesso em: 22 maio 2017.

25. Rannala, B.; Yang, Z. Probability distribution of molecular evolutionary trees: A new method of phylogenetic inference. Journal of Molecular Evolution, v.43, p.304-311, 1996.

26. Ronquist, F.; Heulsenbeck, J.P. MrBayes 3: Bayesian phylogenetic inference under mixed models. Bioinformatics, v.19, p.1572-1574, 2003.

27. Reino, J.L.; Guerrero, R.F.; Hernández-Galán, R.; Collado, I.G. Secondary metabolites from species of the biocontrol agent Trichoderma. Phytochemistry Reviews, v.7, p.89-123, 2008.

28. Santos, P.H.D.; Carvalho, B.M.; Aguiar, K.P.; Aredes, F.A.S.; Poltronieri, T.P.S.; Vivas, J.M.S.; Mussi Dias, V.; Bezerra, G.A.; Pinho, D.B.; Pereira, M.G.; Silveira, S.F. Phylogeography and population structure analysis reveals diversity by mutations in Lasiodiplodia theobromae with distinct sources of selection. Genetics and Molecular Research, v.16, n.2, p. gmr16029681, 2017

29. Schuster, A.; Schmoll, M. Biology and biotechnology of Trichoderma. Applied Microbiology and Biotechnology, v.87, p.787-799, 2010.

30. Tamura, K.; Stecher, G.; Peterson, D.; Filipski, A.; Kumar, S. MEGA 6: Molecular Evolutionary Genetics Analysis Version 6.0. Molecular Biology and Evolution, v.30, p.2725-2729, 2013. 